\title{
New biology institute in Milan prizes quality above loyalty in effort to become world-class
}

Milan. The future of biological research in Italy brightened last month with the opening of an ambitious new research institute in Milan that wants to stand outside the traditional Italian system of staff appointments

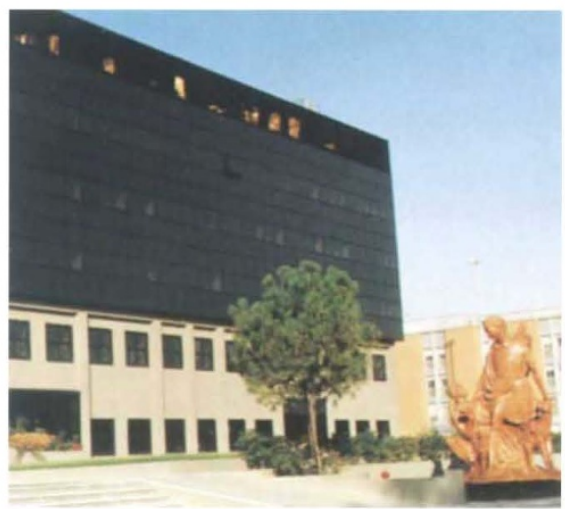

The Dibit Institute

and make its mark internationally.

The Dibit Institute cost more than L10 billion (US\$7.5 million) to build and was financed by the private foundation $\mathrm{H}$. San Raffaele, which runs a large hospital and research centre in Milan. It has attracted some of the best biologists in Italy - a group renowned for its lack of mobility to do research in cell biology and related disciplines, taking advantage of the institute's close links with clinical departments.

Jacopo Meldolesi, the director of research, is determined to break the mould of Italian science by hiring the best people and creating the best possible research environment without feeling an obligation to make appointments on the basis of loyalty to any scientist who has survived long enough in a particular institute. But that system is exactly what geneticist Fulvio Mavilio, who left Naples to join the Dibit Institute, hopes to avoid.

Unhappy with the way research decisions are made in southern Italy, Mavilio is optimistic that Dibit will be different. "The idea here is to focus [on a scientist's] performance, measured in terms of international publications", he says. "Those are criteria not necessarily shared by university teachers or the national research institute here."

Meldolesi, whose own interest in signal transduction and second messenger systems forms one of the major research projects at the new institute, hopes in the next two years to double the current number of scientific staff to around 200. More than a third of the institute's research budget comes from outside sources, including the national research council and the European Communities. Further financial independence is provided

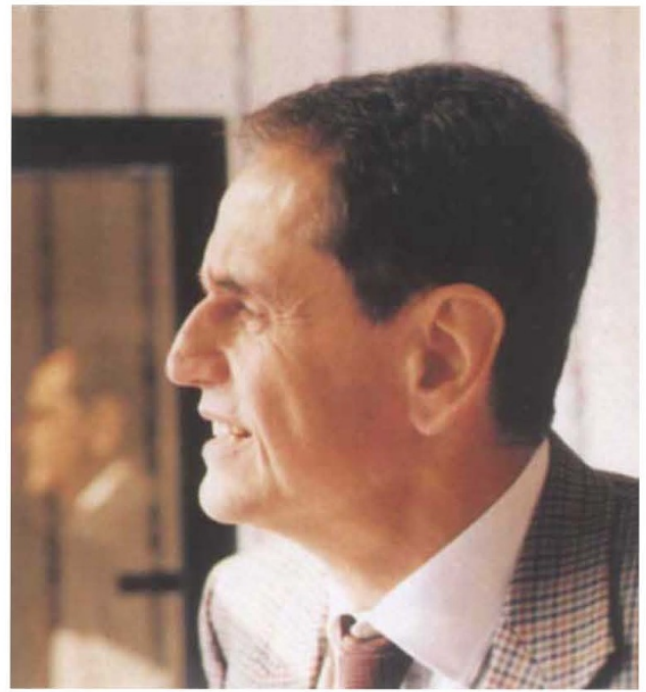

Jacopo Meldolesi

by the drug companies Roche and Bayer, both of which intend to rent space in the institute for fundamental research on drug discovery. Each industrial unit will employ some 30 to 40 scientists.

Italy lags behind such countries as Germany, France and Britain in biology, not to mention the United States. Meldolesi's dream is to create a facility with a reputation to match those of the Institut Pasteur or the Max Planck institutes.

Alison Abbott

\section{Five-year plan cuts funding for Indian laboratories}

New Delhi. India's Council of Scientific and Industrial Research (CSIR) has asked 40 of its laboratories to extend some projects and cancel others after the council's budget for the next five years was cut drastically.

The eighth five-year plan from the Indian Planning Commission approved only $£ 117$ million for the council, less than half of its request for $£ 260$ million for 1992-97. Moreover, the $£ 9$ million allocated for the current year is the lowest in the history of the council, which has enjoyed a steadily rising budget since its formation in 1950. The current budget is enough for only two or three projects in each laboratory.

As a result, many projects beginning this year have been cancelled, while others were either delayed or terminated ahead of schedule. Those abandoned include a high-temperature superconductivity project at the National Physical Laboratory and a very-large baseline interferometry project on studying crustal movements to predict earthquakes.
A $£ 32$-million demonstration plant to demonstrate an indigenously developed technology to generate power through coal gasification has been scrapped, as has a project to convert natural gas into diesel oil using a catalyst developed by CSIR scientists.

The government justified its reduced allocation on the grounds that laboratories should find industrial support for some of their programmes; last year that support totalled $£ 75,000$. But S.K. Joshi, director general of the council, says that the money usually goes towards specific projects and is not available for the council's own efforts. In addition, the government has weakened the council's ability to earn money through the sale of technologies and from royalties by encouraging industries to import what they lack.

In a separate development, the Indian government has decided to shut down the world's deepest underground physics laboratory, ending almost 30 years of research on cosmic ray neutrinos and the world's longest-running experiment to detect proton decay.

The government-owned Bharat Gold Mines Ltd decided that further mining of the 112-year-old Kolar gold fields would be uneconomic; annual gold production at the mines has dropped from 40 tonnes two decades ago to $700 \mathrm{~kg}$. Its decision to cease mining by March 1993 presented laboratory officials with an annual bill of $£ 2$ million (US\$3.8 million) to maintain and operate the shafts, lifts, air conditioning and ventilation systems. But the Tata Institute of Fundamental Research (TIFR), which operates the laboratory, decided to close the facility after failing to win assurances that the government would provide the additional funding.

The gold mine is $4 \mathrm{~km}$ deep and the laboratory extends more than half-way down. In 1965, it was the first to detect interactions of cosmic rays neutrinos, and in 1980, in a collaboration with Japanese scientists, it became the first site to search for proton decay.

K.S. Jayaraman 